\title{
Nature of radioactive contamination in soils of the pine forest in the territory adjacent to Semipalatinsk test site
}

\author{
N.V. Larionova*, A.V. Panitskiy, A.Ye. Kunduzbayeva, \\ A.M. Kabdyrakova, A.R. Ivanova, A.O. Aidarkhanov
}

Branch «Institute of Radiation Safety and Ecology» of the Republican State Enterprise «National Nuclear Center of the Republic of Kazakhstan», Kurchatov, Kazakhstan

\section{- Original article}

*Corresponding authors: Dr. Natalya V. Larionova, E-mail: larionova@nnc.kz

Revised: February 2020 Accepted: March 2020

Int. J. Radiat. Res., January 2021; 19(1): 113-120

DOI: $10.29252 /$ ijrr.19.1.113

\begin{abstract}
Background: This work investigated radioactive contamination in soils of the pine forest in the territory adjacent to Semipalatinsk test site. Materials and Methods: Thirty samples from the soil were collected from six different a soil profile was laid out (research areas). Activity concentrations of ${ }^{137} \mathrm{Cs}$ and ${ }^{241} \mathrm{Am}$ were determined using a Canberra GX-2020 solid-state gammaspectrometer system. Activity concentrations of ${ }^{90} \mathrm{Sr}$ and ${ }^{239+240} \mathrm{Pu}$ were determined after application of radiochemical analysis. In addition, the soil physicochemical characteristics such as $\mathrm{pH}$ value, the amount of organic content and texture of soil were investigated by $\mathrm{pH}$ meter, the Tiurin's techniques, modified by Nikitin, and particle size distribution (Pipette) methods, respectively. Results: The highest specific activity values were registered for ${ }^{241} \mathrm{Am}$ (up to $64 \mathrm{~Bq} / \mathrm{kg}$ ) and ${ }^{239+240} \mathrm{Pu}$ (up to $75 \mathrm{~Bq} / \mathrm{kg}$ ) transuranium radionuclides. Maximum concentrations of ${ }^{241} \mathrm{Am},{ }^{137} \mathrm{Cs}$ and ${ }^{239+240} \mathrm{Pu}$ were registered in the top $5-\mathrm{cm}$ layer, while ${ }^{90} \mathrm{Sr}$ is uniformly distributed up to the depth of $20 \mathrm{~cm}$. In general, researched artificial radionuclides by their level of mobility in vertical soil profile can be arranged in sequence as follows: ${ }^{90} \mathrm{Sr}>{ }^{239+240} \mathrm{Pu}>{ }^{241} \mathrm{Am}>{ }^{137} \mathrm{Cs}$. Conclusion: ${ }^{137} \mathrm{Cs}$ by the character of its distribution in vertical soil profile is similar to its vertical distribution in brown soils at conditionally «background" STS territories. Mobility of ${ }^{241} \mathrm{Am},{ }^{239+240} \mathrm{Pu}$ and ${ }^{90} \mathrm{Sr}$ in brown soils at the researched territory is higher than at conditionally «background» territories of the STS.
\end{abstract}

Keywords: Semipalatinsk Test Site (STS), artificial radionuclides, cesium $\left({ }^{137} \mathrm{CS}\right)$, strontium $\left({ }^{0} \mathrm{Sr}\right)$, americium $\left({ }^{241} \mathrm{Am}\right)$, plutonium $\left({ }^{239+240} \mathrm{Pu}\right)$, soil.

\section{INTRODUCTION}

At the present time there is a lot of information in the global practice on the issues of migration of artificial radionuclides in forest ecosystems. Researches of this kind were made in the zones of contamination resulted from Kyshtym and Chernobyl radiation accidents $(1,2)$. Multiple works aimed at study of radionuclides migration in forest biocenoses were made in the forest landscapes in 30-kilometer compulsory evacuation zone of Chernobyl NPP (Ukraine) and the most contaminated regions of Belarus and of Russian Federation $(3,4,5)$. Fukushima Daiichi NPP (FDNPP) accident that took place in the March, 2011 made a new round in researches of this kind. This accident caused radioactive contamination of a large area, $70 \%$ of that were represented by forests. From the accident at the NPP until now, comprehensive works for research of radiological situation at contaminated forest lands have been conducted in Japan that included determining radionuclides concentration in individual environmental 
components and revealing peculiarities in radionuclides migration there ${ }^{(6-9)}$.

One of the main natural components, where artificial radionuclides get localized is soil. Mobility of radionuclides in soil depends on three main groups of factors as follows: properties of soils, characteristics of radionuclides and climatic conditions. The least mobile radionuclide is ${ }^{137} \mathrm{Cs}$, since soils of whatever composition absorb it virtually completely and the most mobile one is ${ }^{90} \mathrm{Sr}$. Maximum concentrations of radionuclides in forest ecosystems can typically be found in litter and top soil, and each next layer contains less radioactive substances than the previous one $(5,4)$.

Contamination in soils of the pine forest in the territory adjacent to Semipalatinsk test site (STS) was formed 60 years ago after radioactive fallout plume have passed this area as the result of a nuclear test conducted on the 29th of August, 1949. The main objective of this work is to determine concentrations and character of ${ }^{137} \mathrm{Cs},{ }^{90} \mathrm{Sr},{ }^{241} \mathrm{Am}$ and ${ }^{239+240} \mathrm{Pu}$ radionuclides vertical distribution in soils at this territory. Obtained data can be used as input parameters for the models, used to describe radioactive substances behavior and to assess the risk of contamination for forest ecosystem components long after radioactive contamination. Scientific novelty is also explained by transuranium radionuclides $\left({ }^{241} \mathrm{Am},{ }^{239+240} \mathrm{Pu}\right)$ at the territory researched, because the basic data available globally were mainly obtained for ${ }^{137} \mathrm{Cs}$ and ${ }^{90} \mathrm{Sr}$.

\section{MATERIALS AND METHODS}

For the purpose of research, the areas with presumably elevated level of radioactive contamination were chosen. For this purpose, $\beta$-particles flux density and equivalent dose rate (EDR) were measured (10). In total, 6 research areas were equipped (figure 1). At each of research areas a soil profile was laid out. To assess the character of radionuclides migration along the soil profile soil samples were collected in $5 \mathrm{~cm}$ intervals to the depth of $25 \mathrm{~cm}$ (11).

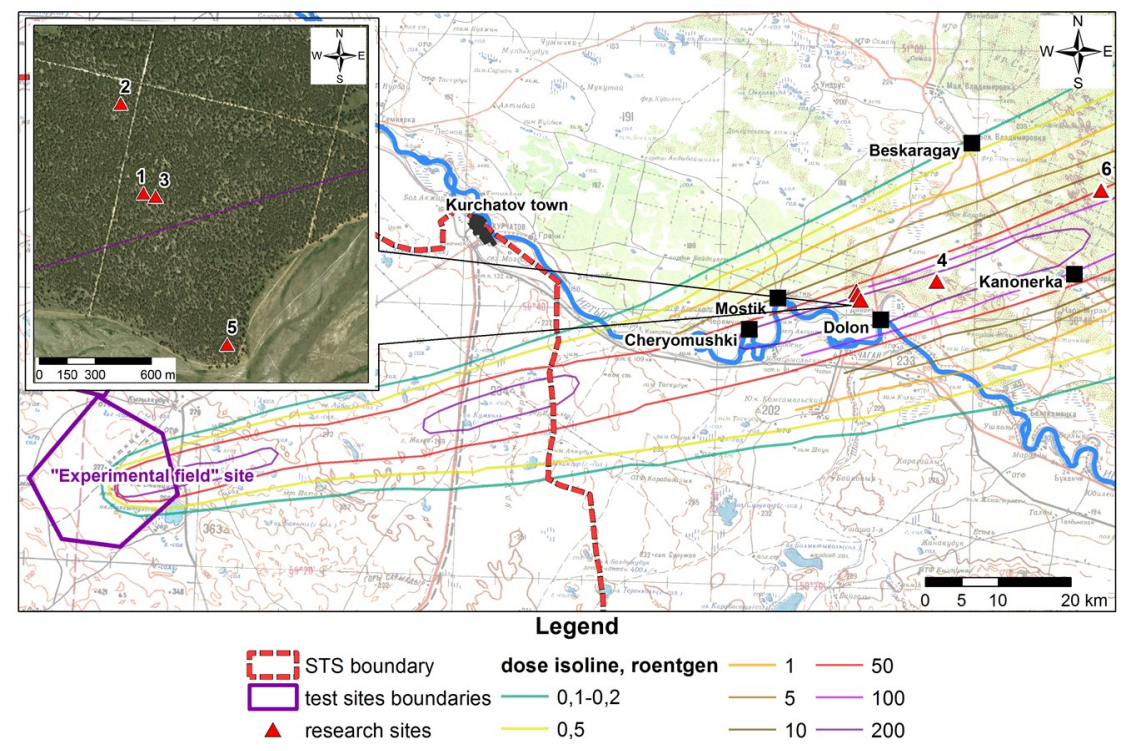

Figure 1. Schematic arrangement of research areas.

Physical and chemical properties of soil were studied only for 3 research areas (sampling point 1, 2 and 3) using the methods generally accepted in soil science $(12,13)$. Soil texture was determined by the pipette-method, which was exploited to define quantitative compositions in percentage ratio of soil fractions that include one or another group of various size particles). The Tiurin's technique, modified by Nikitin, was applied to determine the humus content of soils (14). Measurement of the $\mathrm{pH}$ level was accomplished through a method based on the 
rock-water extract's $\mathrm{pH}$ gauging with an electrode system that includes an indicator glass electrode, which potential is determined by the hydrogen ions activity in solution, and a subsidiary flowing comparison electrode with a known potential.

Before the radionuclide analysis, soil samples were dried in drying cabinets at the temperature of $50-60^{\circ} \mathrm{C}$ to air-dry state. After removal of coarse rocks and inclusions (plant residues) dried samples were weighted using technical scales. Next, the whole sample mass was carefully mixed, with gradual mashing in porcelain mortar using a beater and sieved through $1 \mathrm{~mm}$ mesh. To check the completeness of sieving, each mesh was shaken over a sheet of paper.

Activity of radionuclides in soil samples was measured according to standardized practices using calibrated equipment $(14,15)$. Activity concentrations of ${ }^{137} \mathrm{Cs}$ and ${ }^{241} \mathrm{Am}$ were determined using a Canberra GX-2020 solid-state gamma-spectrometer system. Activity concentrations of ${ }^{90} \mathrm{Sr}$ and $239+240 \mathrm{Pu}$ were determined after application of radiochemical analysis.

The radiochemical procedure for extraction and isolation of ${ }^{90} \mathrm{Sr}$ and ${ }^{239+240} \mathrm{Pu}$ is formed, briefly, by several stages: leaching out of radionuclides from the soil matrix by complete chemical decomposition, removal of interfering radionuclides, preparation of counting samples and determination of the corresponding activity concentrations. In detail the procedure is as follows: 5-10 g of the selected subsample are initially ashed in a muffle furnace at a temperature of 6500C during 6-8 hours. Known amounts of ${ }^{242} \mathrm{Pu}$ tracer and stable strontium are added previously to the sample. In fact, $250 \mathrm{mg}$ of strontium carrier are added per sample while the activity of ${ }^{242} \mathrm{Pu}$ added is $50 \%$ of the expected ${ }^{239+240} \mathrm{Pu}$ content in the sample, which is determined with basis in the previous ${ }^{241} \mathrm{Am}$ determination by gamma-ray spectrometry and the use of an accepted value for the ${ }^{241} \mathrm{Am} /{ }^{239+240} \mathrm{Pu}$ activity ratio of $1 / 10$ in the areas analyzed.

After ashing, a full acid sample decomposition was performed using concentrated hydrofluoric acid (HF) and a mixture of concentrated hydrofluoric and nitric acids $\left(\mathrm{HNO}_{3}\right)$, being the fluorine traces removed by using boric acid $\left(\mathrm{H}_{3} \mathrm{BO}_{3}\right)$. From the resulting solution, the $\mathrm{Pu}$ was stabilized as $\mathrm{Pu}$ (IV), chromotografically purified and isolated, by using a styrene-divinylbenzene copolymer based strongly basic anion resin (trade mark AB-17-8, Russia).

Finally, by electrolytic precipitation of $\mathrm{Pu}$ on a steel plate, a counting sample was obtained ( $\alpha$-source). This electrolytic precipitation was carried out at the current rate of $1.4 \mathrm{~A}$ and voltage of $12 \mathrm{~V}$ for $60 \mathrm{~min}$. The activity concentrations of ${ }^{239+240} \mathrm{Pu}$ in the $\alpha$ sources were determined by using an Alpha Analyst alpha-spectrometer (CANBERRA, USA), equipped with solid-state PIPS detectors.

On the other hand, the strontium was precipitated as oxalates from the solution purified of $\mathrm{Pu}$. The strontium precipitate, after filtering, was dissolved in diluted hydrochloric acid $(\mathrm{HCl})$, and the resulting solution was purified twice of three-valence metals by precipitating them as hydroxides using a concentrated ammonia solution. Then, $1 \mathrm{~cm}^{3}$ of yttrium carrier was added to the purified solution (carrier concentration of $50 \mathrm{mg} / \mathrm{cm}^{3}$ ), and the solution was aged during 14 days in order to allow the growing of Y-90. After this aging step, the yttrium was co-precipitated as hydroxides by adding ammonia solution until reach a $\mathrm{pH}$ 7-8, and the Y-90 activity concentration was determined after being dissolved the precipitate with a diluted hydrochloric acid $(\mathrm{HCl})$ solution, by using a liquid scintillation beta-spectrometer "TRI CARB 3100 TR". The chemical yttrium yield was determined by atomic emission spectrometry (ICP-AS) and the ${ }^{90} \mathrm{Sr}$ activity concentration was determined from the activity concentration of Y-90. Additionally, after Y-90 was co-precipitated, the strontium chemical yield was determined in the filtrate by atomic emission spectrometry (ICP-AS).

Detection limits for ${ }^{137} \mathrm{Cs}$ in soil samples was $0.1 \mathrm{~Bq} / \mathrm{kg},{ }^{241} \mathrm{Am}-0.5 \mathrm{~Bq} / \mathrm{kg},{ }^{239+240} \mathrm{Pu}-0.5 \mathrm{~Bq} /$ $\mathrm{kg}$ and ${ }^{90} \mathrm{Sr}-0.8 \mathrm{~Bq} / \mathrm{kg}$. Inaccuracy of measurements of ${ }^{137} \mathrm{Cs}$ and ${ }^{241} \mathrm{Am}$ did not exceed $10-20 \%,{ }^{90} \mathrm{Sr}-15-25 \%,{ }^{239+240} \mathrm{Pu}-30 \%$. 
The statistical analysis is the science of collecting, exploring and presenting large amounts of data to discover underlying patterns and trends. Statistics are applied every day - in research and industry to become more scientific about decisions that need to be made. The environmental system could be managed through the multivariate treatment of environmental data which is commonly used to describe the relationship of the variables. The main statistical software used was Microsoft Office 2010.

\section{RESULTS AND DISCUSSION}

To identify the type of researched soils, their physical and chemical characteristics as follows were determined (for the sites 1, 2 and 3): amount of absorbed bases, amount of organic matter (humus), carbonates, water-soluble salts as well as $\mathrm{pH}$ of soil solution and mechanical composition $(<0,01 \mathrm{~mm})$ (table 1$)$.

Upon the results of analyses, soils were identified as sandy (lose sand, bound sand). Soils are non-saline, the content of watersoluble salts does not exceed $0.06 \%$. These soil contain a little humus content (average of $0.3-1.6 \%$ ), reaction of soil solutions ranges in between neutral and weakly alkaline (6.8-7.4). Carbonates were washed out. Concentration of calcium and magnesium is insignificant (total concentration ranges between 3.8 and 4.8 mmol/100g), the main components of absorbed bases is calcium (3.2-4.4 mmol/100g). According to the characteristics listed above, the soils belong to brown soils.

Table 2 provides results of laboratory analysis for determining specific activity of ${ }^{137} \mathrm{Cs}$, ${ }^{90} \mathrm{Sr},{ }^{241} \mathrm{Am},{ }^{239+240} \mathrm{Pu}$ artificial radionuclides in the soil researched.

The table shows, that the highest specific activity values at the researched territory are typical for ${ }^{241} \mathrm{Am}$ and ${ }^{239+240} \mathrm{Pu}$ transuranium radionuclides (up to $64 \mathrm{~Bq} / \mathrm{kg}$ and $75 \mathrm{~Bq} / \mathrm{kg}$ respectively). Specific activity of ${ }^{137} \mathrm{Cs}$ in most of the cases is below the detection limit of equipment and methodology used, the maximum value was registered at the site $6(75 \mathrm{~Bq} / \mathrm{kg})$. Quantitative values of ${ }^{90} \mathrm{Sr}$ specific activity was found in all the collected samples, however the maximum values do not exceed $8.3 \mathrm{~Bq} / \mathrm{kg}$.

Character of radionuclides distribution in vertical profile is shown in diagrams (figure 2).

Table 1. Physical and chemical properties of the researched soils.

\begin{tabular}{|c|c|c|c|c|c|c|c|c|c|}
\hline \multirow{2}{*}{$\begin{array}{c}\text { Sampling } \\
\text { point }\end{array}$} & \multirow{2}{*}{$\begin{array}{l}\text { Sampling } \\
\text { depth, cm }\end{array}$} & \multicolumn{3}{|c|}{ Absorbed bases, $\mathrm{mmol} / 100 \mathrm{~g}$} & \multirow{2}{*}{$\mathrm{pH}$} & \multirow{2}{*}{$\begin{array}{c}\text { Organic } \\
\text { matter } \\
\text { (humus), \% }\end{array}$} & \multirow{2}{*}{$\begin{array}{c}\text { Carbonates, } \\
\%\end{array}$} & \multirow{2}{*}{$\begin{array}{c}\text { Water-soluble } \\
\text { salts, } \%\end{array}$} & \multirow{2}{*}{$\begin{array}{c}\text { Mechanical } \\
\text { composition, } \\
<0,01 \mathrm{~mm}\end{array}$} \\
\hline & & $\mathrm{Ca}$ & $\mathrm{Mg}$ & total & & & & & \\
\hline \multirow{5}{*}{1} & $0-3$ & 3.6 & 0.8 & 4.4 & 6.9 & 1.1 & no & 0.042 & 4.18 \\
\hline & $3-16$ & 3.6 & 0.8 & 4.4 & 7.3 & 0.8 & no & 0.045 & 4.18 \\
\hline & $16-30$ & 3.6 & 0.6 & 4.2 & 7.4 & 0.3 & no & 0.049 & 2.45 \\
\hline & $30-50$ & 3.2 & 0.6 & 3.8 & 7.3 & 1.0 & no & 0.046 & 3.53 \\
\hline & $50-100$ & 3.6 & 0.6 & 4.2 & 7.2 & 0.4 & no & 0.046 & 3.45 \\
\hline \multirow{5}{*}{2} & $0-5$ & 4.8 & 0 & 4.8 & 6.8 & 2.2 & no & 0.052 & 4,74 \\
\hline & $5-20$ & 4.0 & 0.4 & 4.4 & 6.9 & 1.6 & no & 0.051 & 4.17 \\
\hline & $20-40$ & 3.6 & 0.4 & 4.0 & 7.2 & 1.0 & no & 0.046 & 6.58 \\
\hline & $40-60$ & 4.0 & 0.4 & 4.4 & 7.0 & 3.0 & no & 0.054 & 5.3 \\
\hline & $60-100$ & 3.6 & 0.4 & 4.0 & 7.4 & 0.4 & no & 0.056 & 3.53 \\
\hline \multirow{5}{*}{3} & $0-5$ & 3.6 & 0.6 & 4.2 & 7.2 & 0.3 & no & 0.050 & 4.9 \\
\hline & $5-20$ & 3.2 & 0.4 & 3.6 & 7.0 & 0.9 & no & 0.053 & 4.58 \\
\hline & $20-40$ & 3.2 & 0.4 & 3.6 & 7.1 & 1.0 & no & 0.051 & 5.3 \\
\hline & $40-60$ & 3.6 & 0.4 & 4.0 & 7.2 & 1.6 & no & 0.050 & 5.46 \\
\hline & $60-100$ & 4.4 & 0.4 & 4.8 & 6.6 & 6.8 & no & 0.060 & 6.77 \\
\hline
\end{tabular}


Table 2. Specific activity of ${ }^{137} \mathrm{Cs},{ }^{90} \mathrm{Sr},{ }^{241} \mathrm{Am},{ }^{239+240} \mathrm{Pu}$ artificial radionuclides

\begin{tabular}{|c|c|c|c|c|c|}
\hline \multirow{2}{*}{ Site № } & \multicolumn{5}{|c|}{ Specific activity of radionuclides, $\mathrm{Bq} / \mathrm{kg}$} \\
\hline & $0-5 \mathrm{~cm}$ layer & 5-10 cm layer & $10-15 \mathrm{~cm}$ layer & $15-20 \mathrm{~cm}$ layer & $20-25 \mathrm{~cm}$ layer \\
\hline \multicolumn{6}{|c|}{${ }^{137} \mathrm{Cs}$} \\
\hline 1 & $<0.1$ & $<0.1$ & $<0.1$ & $<0.1$ & $<0.1$ \\
\hline 2 & $<0.1$ & $<0.1$ & $<0.1$ & $<0.1$ & $<0.1$ \\
\hline 3 & $<0.1$ & $<0.1$ & $<0.1$ & $<0.1$ & $<0.1$ \\
\hline 4 & $2.2 \pm 0.4$ & $0.26 \pm 0.14$ & $<0.1$ & $<0.1$ & $<0.1$ \\
\hline 5 & $<0.1$ & $0.15 \pm 0.07$ & $<0.1$ & $<0.1$ & $<0.1$ \\
\hline 6 & $25 \pm 5$ & $8.4 \pm 1.7$ & $0.5 \pm 0.2$ & $0.24 \pm 0.11$ & $<0.1$ \\
\hline \multicolumn{6}{|c|}{${ }^{90} \mathrm{Sr}$} \\
\hline 1 & $3.3 \pm 0.6$ & $<0.8$ & $3.5 \pm 0.7$ & $3.2 \pm 0.7$ & $1.4 \pm 0.6$ \\
\hline 2 & $6.4 \pm 1$ & $8.3 \pm 1.2$ & $5.6 \pm 0.8$ & $3 \pm 0.6$ & $1.4 \pm 0.6$ \\
\hline 3 & $5.6 \pm 0.8$ & $1.3 \pm 0.6$ & $<0.8$ & $1.5 \pm 0.7$ & $1.5 \pm 0.3$ \\
\hline 4 & $30 \pm 4$ & $69 \pm 10$ & $38 \pm 6$ & $43 \pm 6$ & $106 \pm 16$ \\
\hline 5 & $14 \pm 2$ & $3.5 \pm 0.7$ & $67 \pm 10$ & $3.7 \pm 0.6$ & $6 \pm 1$ \\
\hline 6 & $7 \pm 1$ & $9.3 \pm 1.4$ & $5.1 \pm 0.8$ & $5.4 \pm 0.8$ & $10.4 \pm 1.6$ \\
\hline \multicolumn{6}{|c|}{${ }^{241} \mathrm{Am}$} \\
\hline 1 & $3.4 \pm 0.7$ & $<0.5$ & $1.9 \pm 0.4$ & $0.9 \pm 0.3$ & $<0.5$ \\
\hline 2 & $64 \pm 13$ & $38 \pm 8$ & $4.2 \pm 0.8$ & $<0.5$ & $<0.5$ \\
\hline 3 & $19 \pm 4$ & $4.1 \pm 0.8$ & $1.1 \pm 0.4$ & $<0.5$ & $<0.5$ \\
\hline 4 & $<0.5$ & $<0.5$ & $<0.5$ & $<0.5$ & $<0.5$ \\
\hline 5 & $<0.5$ & $<0.5$ & $<0.5$ & $<0.5$ & $<0.5$ \\
\hline 6 & $0.8 \pm 0.2$ & $0.6 \pm 0.2$ & $<0.5$ & $<0.5$ & $<0.5$ \\
\hline \multicolumn{6}{|c|}{${ }^{239+240} \mathrm{Pu}$} \\
\hline 1 & $1.5 \pm 0.6$ & $<0.5$ & $1.0 \pm 0.4$ & $<0.5$ & $<0.5$ \\
\hline 2 & $49 \pm 5$ & $59 \pm 4$ & $6.3 \pm 1.0$ & $6.1 \pm 1.2$ & $<0.5$ \\
\hline 3 & $75 \pm 5$ & $23 \pm 3$ & $<0.5$ & $<0.5$ & $<0.5$ \\
\hline 4 & $2.7 \pm 0.8$ & $<0.5$ & $1.9 \pm 0.9$ & $<0.5$ & $2.2 \pm 0.9$ \\
\hline 5 & $<0.5$ & $<0.5$ & $<0.5$ & $<0.5$ & $<0.5$ \\
\hline 6 & $23 \pm 4$ & $<0.5$ & $3.6 \pm 0.5$ & $<0.5$ & $<0.5$ \\
\hline
\end{tabular}

- site $1 \square$ site $2 \Delta$ site $3 \quad$ osite 4 * site $5 \times$ site 6
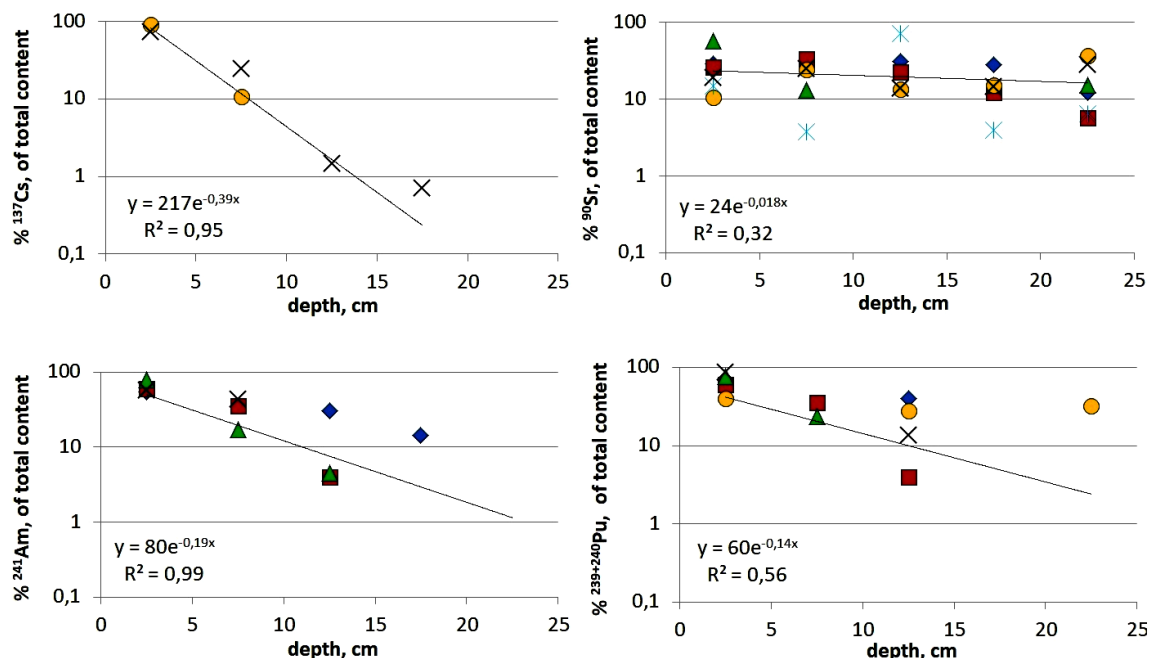

Figure 2. Vertical distribution of radionuclides in soils. 
The average percentage of ${ }^{137} \mathrm{Cs},{ }^{241} \mathrm{Am}$ and $239+240 \mathrm{Pu}$ in $0-5 \mathrm{~cm}$ layer is $81,3 \%, 50,2 \%$ and $60,7 \%$ of its total concentration in soil vertical profile respectively. At the depth of up to $10 \mathrm{~cm}$ $98,9 \%$ of ${ }^{137} \mathrm{Cs}$ concentration, $69,3 \%$ and 75,2 $\%$ of ${ }^{241} \mathrm{Am}$ and $239+240 \mathrm{Pu}$ concentration respectively was registered.

The percentage of ${ }^{90} \mathrm{Sr}$ in $0-5 \mathrm{~cm}$ layer is 25.9 $\%$, and further, up to $20 \mathrm{~cm}$ deep the radionuclide is distributed virtually uniformly. At the depth of up to $10 \mathrm{~cm}$, only $42.5 \%$ of the total concentration found in the researched vertical soil profile was registered. High mobility of ${ }^{90} \mathrm{Sr}$ in this case can be caused by its higher migration ability due to good solubility.

It is known, in general, that some regularities can be observed in changes of radionuclides concentrations in vertical profile of forest soils. First of all, the most intensive distribution of radionuclides occurs in the first year or two after radionuclides enter the soil. Concentration of radioactive substances in vertical soil profile can be well described by exponential relationships. In course of time, radionuclides get redistributed in vertical soil profile - their activity decreases in top soil layers and vice versa, their activity in deep soil layers increases (4). The data obtained on vertical distribution of radionuclides in soils at this territory (described by exponential relationships) also demonstrate their deepening in course of time. Most clearly the increase in concentration was observed for ${ }^{90} \mathrm{Sr}$, and less intensive increase was registered for ${ }^{241} \mathrm{Am}$ and ${ }^{239+240} \mathrm{Pu}$.

Since upon the results of soils physical and chemical properties analyses (table 1) they were identified as brown soils, for comparison purposes, the data on vertical distribution of ${ }^{137} \mathrm{Cs}, \quad{ }^{90} \mathrm{Sr}, \quad{ }^{241} \mathrm{Am}, \quad{ }^{239+240} \mathrm{Pu}$ artificial radionuclides in brown soils at conditionally «background» territories of the STS were considered (16) (table 3).

Table 3. Curve functions for vertical distribution of radionuclides in brown soils.

\begin{tabular}{|c|c|c|}
\hline Radionuclide & $\begin{array}{c}\text { Brown soils at conditionally } \\
\text { «background » territories of the STS }{ }^{(16)}\end{array}$ & Brown soils of pine forest near Irtysh river \\
\hline${ }^{241} \mathrm{Am}$ & $\mathrm{y}=85 \mathrm{e}^{-0,3 x}$ & $\mathrm{y}=80 \mathrm{e}^{-0,2 x}\left(\mathrm{R}^{2}=0,99\right)$ \\
\hline${ }^{137} \mathrm{Cs}$ & $\mathrm{y}=125 \mathrm{e}^{-0,4 \mathrm{x}}$ & $\mathrm{y}=217 \mathrm{e}^{-0,4 x}\left(\mathrm{R}^{2}=0,95\right)$ \\
\hline${ }^{90} \mathrm{Sr}$ & $\mathrm{y}=79 \mathrm{e}^{-0,1 \mathrm{x}}$ & $\mathrm{y}=24 \mathrm{e}^{-0,02 x}\left(\mathrm{R}^{2}=0,32\right)$ \\
\hline${ }^{239+240} \mathrm{Pu}$ & $\mathrm{y}=126 \mathrm{e}^{-0,4 \mathrm{x}}$ & $\mathrm{y}=60 \mathrm{e}^{-0,1 x}\left(\mathrm{R}^{2}=0,56\right)$ \\
\hline
\end{tabular}

Using the data, given for comparison, we can state, that the character of ${ }^{137} \mathrm{Cs}$ radionuclide distribution in the vertical soil profile of the territory researched is similar with the character of its vertical distribution in brown soils at conditionally «background» STS lands. So the $10 \mathrm{~cm}$ thick soil layer of soil contains up to $98.9 \%$ and $94.9 \%$ of ${ }^{137} \mathrm{Cs}$ (of the total Specific activity in the profile) respectively. Unlike ${ }^{137} \mathrm{Cs}$, mobility of ${ }^{241} \mathrm{Am},{ }^{239+240} \mathrm{Pu}$ and ${ }^{90} \mathrm{Sr}$ at the researched territory is higher. In the layers at the depth of more than $10 \mathrm{~cm}$, percentage of these radionuclides was found to be increased comparing with their distribution in brown soils at conditionally «background» territories of the STS.
It's known, that physical and chemical properties of soils play the core role in migration of radionuclides. So, with increase of sorption capacity of soils, migration capability of radionuclides decreases (4).

Normal brown soils at conditionally «background» territories of the STS has moderate humus content - 3.5-5.0 \%. (Humus content at the territory of Semipalatinsk Test Site exceeds the generally accepted values for all types and subtypes of soils by 20-30\% that results from a long reserve status given to this area during the nuclear tests). Thickness of humus layers $(A+B 1)$ ranges between 15 and 40 $\mathrm{cm}$. mainly light clay loam, and less frequently clay loam soil types can be found here. Normal 
brown soils are weakly salted with easily-soluble salts, water suspensions show the reaction ranging between neutral and weakly alkaline (20).

So, brown soils at the researched area have lower humus content and lighter mechanical composition comparing with conditionally «background» territories. The factors listed before decrease the sorption capacity of soils that in its turn can be one of the reasons for more intensive migration of radionuclides along the researched soils profile.

Another reason can be the speciation of radionuclides in soils. It can be assumed, that chemical speciation's of radionuclides and their solubility will depend on dispersive capacity and characteristics of deposited particles and therefore, on the distance between the point and the epicenter of explosion. Therefore at conditionally «background» territories of the STS radionuclides were found to be in more bound form, while at the adjacent researched area they were found in more soluble form. Such an effect was also registered before 0 , when right after the test, to study solubility of fallouts, sampled at the nearest «plume», samples were treated by distilled water, with further separation of particles by means of centrifuging. Then the isotopic composition of solution and solid phase was determined. As the result, the dependence of increase in solubility of isotopes (in particular, of ${ }^{90} \mathrm{Sr}$ ) on the distance along the axis of the "plume» was obtained.

However, as the result of practical researches, conducted at the territory adjacent to the STS 0, tightly-bound forms of ${ }^{137} \mathrm{Cs},{ }^{241} \mathrm{Am}$, ${ }^{239+240} \mathrm{Pu}$ were found to dominate among their speciation in soils of the pine forest. This radionuclides distribution pattern was registered for soils at the majority of the STS objects. At that, by the character of ${ }^{90} \mathrm{Sr}$ speciation distribution the researched territory has more bound forms, than the «background» territories. So, higher migration ability of radionuclides at the territory researched comparing with conditionally «background» territories, most probably depends less on forms of occurrence than on physical and chemical properties.

Int. J. Radiat. Res., Vol. 19 No. 1, January 2021

\section{CONCLUSIONS}

As the result of researches, conducted in pine forest at the territory, adjacent to the STS, increased concentrations of all the radionuclides considered $\left({ }^{241} \mathrm{Am},{ }^{90} \mathrm{Sr},{ }^{137} \mathrm{Cs},{ }^{239+240} \mathrm{Pu}\right)$ were registered. The highest specific activity values were registered for ${ }^{241} \mathrm{Am}$ (up to $64 \mathrm{~Bq} / \mathrm{kg}$ ) and $239+240 \mathrm{Pu}$ (up to $75 \mathrm{~Bq} / \mathrm{kg}$ ) transuranium radionuclides. Maximum concentrations of ${ }^{241} \mathrm{Am},{ }^{137} \mathrm{Cs}$ and ${ }^{239+240} \mathrm{Pu}$ were registered in the top $5-\mathrm{cm}$ layer, while ${ }^{90} \mathrm{Sr}$ is uniformly distributed up to the depth of $20 \mathrm{~cm}$. In general, the obtained results are very close to those reported in the literature.

\section{ACKNOWLEDGEMENT}

This work was financially supported by the Ministry of Education and Science of the Republic of Kazakhstan within the framework of the scientific grant AP05130568 "Researching into radionuclide redistribution in forest ecosystems in the long-term period after nuclear tests at Semipalatinsk test site».

\section{Conflicts of interest: Declared none.}

\section{REFERENCES}

1. Aleksakhin R, Naryshkin M (1977) Migration of radionuclides in forest biogeocenozes. Moscow. USSR: 144.

2. Kulikov N, Molchanova I, Karavaeva E (1990) Radioecology of soil and vegetation cover. Sverdlovsk. UrD AS USSR: 172.

3. Tihomirov F (1993) Distribution and migration of radionuclides in EURT forests in case of radioactive fallouts. Ecological consequences of the emergency in South Ural. Moscow. USSR: 21-39.

4. Perevolotskiy A (2006) Distributions of $137 \mathrm{Cs}$ and $90 \mathrm{Sr}$ in forest biogeocenoses. Institute of Radiology, Gomel, Republic of Belarus: 255.

5. Shcheglov A, Tsvetnova O, Klyashtorin A (2001) Biogeochemical migration of technogenic radionuclides in forest ecosystems. Moscow. Russian Federation: 235.

6. Yoshihara T, Matsumura H, Tsuzaki M, Wakamatsu T, Kobayashi T, Hashida S-n, Nagaoka T, Goto F (2014) Changes 


\section{Larionova et al. / Radioactivity in soils of Semipalatinsk test site}

in radiocesium contamination from Fukushima in foliar parts of 10 common tree species in Japan between 2011 and 2013. Journal of Environmental Radioactivity, 138: 220-226.

7. Yoshihara T, Hashida S-n, Abe K, Ajito H (2014) A time dependent behavior of radiocesium from the Fukushimafallout in litterfalls of Japanese flowering cherry trees. Journal of Environmental Radioactivity, 127: 34-39.

8. Endo I, Ohte N, Iseda K, Tanoi K, Kobayashi N, Murakami M, Tokuchi N, Ohashi M (2015) Estimation of radioactive 137-cesium transportation by litterfall, stemflow and throughfall in the forests of Fukushima. Journal of Environmental Radioactivity, 149: 176-185.

9. Yoschenko V, Takase T, Konoplev A, Nanba K, Onda $Y$, Kivva S, Zheleznyak M, Sato N, Keitoku K (2017) Radiocesium distribution and fluxes in the typical Cryptomeria japonica forest at the late stage after the accident at Fukushima Dai-Ichi Nuclear Power Plant. Journal of Environmental Radioactivity, 166: 45-56.

10. Shcheglov A, Tsvetnova O, Klyashtorin A (2001) Biogeochemical migration of technogenic radionuclides in forest ecosystems. Moscow. Russian Federation: 235.

11. GOST 17.4.3.01-83 (1998). Environmental Protection. Soils. General Requirements for Soil Sampling. Introduction. 1984-01-07. Collection. Environmental protection. Soils. Standards publisher: 29-31.

12. GOST 12536-2014 (2015) Soils. Methods of in-vitro determination of granulometric and micro aggregate composition. Instead of GOST 12536-1979; 2016-09-01 introduced. Standartinform: 18.

13. GOST 26213-91 (1992) Soils. Methods of determining organic matter. Instead of GOST 26213-84; 1991-12-29 was introduced. Publishing house of standards: 6.

14. Dyusenbekov Z (1998) Collection of methodology instructions for laboratory studies of soils and vegetation of the Republic of Kazakhstan. State Research and Development
Center for Earth Resourses and Land Arrangement. Almaty: 128-130.

15. GOST 26423-85. - GOST 26428-85 (1985) Soils. Methods of determining cathode-anion composition of water extract. Introduction. 1985-02-18. Publishing house of standards: 10.

16. GOST 26487-85 (1985) Soils. Determining calcium in exchangeable form and mobile magnesium using CSRIAS. Introduction. 1985-03-26. Publishing house of standards: 33.

17. GOST 17.5.4.01-84 (1985) Method of determination of $\mathrm{pH}$ in water extracts of soils. Environment protection. Land rehabilitation. Introduction. 1985-07-01. Publishing house of standards: 2.

18. M I 2143-91 RK "Activity of radionuclides in volumetric samples. Technique for measurement using beta- spectrometer».

19. Methods for determination of concentration of artificial radionuclides of plutonium-(239, 240), strontium-90 in environmental objects (soils, subsoils, bottom sediments and plants) KZ.07.00.00471 (2005).

20. Panitskiy A, Lukashenko S, Magasheva R (2016) Peculiarities in vertical distribution of radionuclides in soils of conditionally clean territory of Semipalatinsk Test Site. Radiation biology. Radioecology, 56: 623-638.

21. Izrael Yu, Petrov V, Pressman A, Rovinskiy F (1970) Radioactive contamination of natural envirnments as the result of underground nuclear explosions and forecasting methods. Leningrad. USSR: 41-42.

22. Kunduzbayeva A, Kabdyrakova A, Lukashenko S (2018) Speciations of artificial radionuclides in soils of forest ecosystems, subjected to fallouts from surfcae nuclear tests at Semipalatinsk Test Site. Radiobiology: topical issues: Proceedings of scientific conferrence, 27-28 September. Gomel. Republic of Belarus: 76-79. 